\title{
PEMBELAJARAN MATEMATIKA DI SEKOLAH DASAR BERBASIS KETERAMPILAN BERPIKIR SEBAGAI ALTERNATIF IMPLEMENTASI KBK
}

\author{
Weldi Bahari \\ Surel: Weldibahari@gmail.com
}

\begin{abstract}
Deeply exploring the contents of Law Number 20 of 2003 concerning the Indonesian education system, it can be drawn two important aspects that must be achieved by elementary education institutions, namely: providing a basis for life in society, and can continue education. Mathematics education in Indonesia needs to be reformed, especially in the Teacher learning strategies used by teachers. This is because until now many students complain and experience difficulties in learning mathematics. Mathematics is a ghost that is frightening to most elementary school students. This is because one of the characteristics of mathematics learning is abstract.
\end{abstract}

Keywords: Mathematics, Learning, Mind Based Learning.

\begin{abstract}
ABSTRAK
Menyelami secara mendalam isi Undang-Undang Nomor 20 tahun 2003 tentang sistem pendidikan RI, maka dapat ditarik 2 sisi penting yang mesti dicapai oleh lembaga pendidikan SD, yaitu : memberikan dasar untuk hidup dalam masyarakat, dan dapat melanjutkan pendidikan. Pendidikan MMatematika di Indonesia perlu direformasi, terutama pada strategi pembelajaran Guru yang digunakan oleh guru. Hal ini disebabkan sampai saat sekarang siswa banyak mengeluh dan mengalami kesulitan dalam belajar Matematika. Matematika menjadi hantu yang menakutkan bagi sebahagian besar siswa sekolah dasar. Hal ini karen salah satu satu karakteristik pembelajaran Matematika yang bersifat abstrak.
\end{abstract}

Kata Kunci: Pembelajaran, Matematika, Belajar Berbasis Pikiran.

\section{PENDAHULUAN}

Dua persoalan penting yang menjadi latar belakang penulisan makalah ini. Pertama, tantangan lembaga pendidikan dasar merupakan sebuah lembaga pendidikan formal yang mempunyai sangat strategis dalam mempersiapkan masyarakat modern yang sangat cepat berubah seiring dengan perubahan Ilmu Pengetahuan dan Teknologi dalam era globalisasi. Kedua, masalah kualitas pendidikan yang dianggap masih sangat rendah baik ditinjau dan sudut proses maupun dan sudut hasil, khususnya dalam pembelajaran Matematika di $\mathrm{SD}$, sehingga muncul berbagai kritikan tajam terhadap proses pembelajaran mata pelajaran ini. Atas dasar kedua hal tersebut, diperlukan pengembangan berbagai model pembelajaran yang diharapkan dapat meningkatkan kualitas pembelajaran. Jika kualitas pembelajaran rneningkat, diharapkan kualitas basil belajar siswa meningkat pula. Berdasarkan 
Undang-Undang Nomor 20 tahun 2003 tentang Sistem Pendidikan Nasional (SISPENAS) telah dijelaskan bahwa "pendidikan nasional berfungsi mengembangkan kemampuan dan membentuk watak serta peradaban bangsa yang bermartabat..., dan menjadi warga negara yang dernokratis dan bertanggung jawab (Pasal. 3). Sebagai bagian dan sistem pendidikan nasional "pendidikan dasar nierupakan jenjang pendidikan yang melandasi jenjang pendidikan rnencngah PasaI 17, ayat. 1).

Dari pernyataan UndangUndang Nomor 20 tahun 2003 (SISPENAS) tersebut, setidaknya kita dapat memahami 2 sisi penting yang akan diraih dan mesti dicapai oleh lembaga pendidikan ini, yaitu: (a) memberikan dasar untuk hidup dalam masyarakat, dan (b) dapat melanjutkan pendidikan.

Berbicara tentang kehidupan bermasyarakat sebagai sasaran pertama yang secara terus menerus mengalami perubahan, menuntut pendidikan dasar untuk "mau dan mampu" mengadaptasi diri dengan perkembangan yang terjadi. Sehingga pengalaman belajar yang diberikan sekolah, menurut Zhou (2000: 11) "tetap relevan dan bermanfaat bagi kehidupan siswa dalam waktu yang lama”.

Selanjutnya Conny (1993: 19),dalam arti kehidupan masyarakat, fungsi SD tidak sematamata menjadikan lulusan yang melek huruf saja, yang memiliki segudang pengetahuan sesaat, dalam arti kurang dapat membantu mewujudkan kemandirian diri siswa. Lulusan SD rnenurutnya, di samping harus melek huruf dalam arti melek teknologi dan melek pikir (thinking literacy) juga arus berbudaya, yang secara menyeluruh disebut juga melek kebudayaan (cultural literacy).

Sebagai sasaran kedua yang mesti dicapai oleh SD ialah mampu mempersiapkan lulusan untuk bisa melanjutkan pendidikan pada jenjang yang lebih tinggi. Hal ini mengandung makna, bahwa kualitas yang dihasilkan SD menjadi penentu dapat atau tidaknya siswa melanjutkan pendidikan di jenjang Sekolah Menengah Pertama (SMP) (bagian dari pendidikan dasar 9 tahun). Perlu juga dipahami, dalam konteks yang lebih luas SD menjadi pondasi yang sangat besar peranannya dalam meletakkan dasar-dasar kualitas SDM untuk daya pembangunan diberbagai aspek kehidupan bangsa.

Pendidikan Matematika di Indonesia direformasi, terutama pada strategi pengajarannya, hal ini disebabkan sampai sekarang, siswa hanyak yang mengeluh dan mengalami kesulitan dalam belajar Matematika. Matematika menjadi hantu yang menakutkan bagi sebahagian besar siswa, akibatnya mereka tidak menyenangi bahkan benci pada pelajaran Matematika. Salah satu karakteristik Matematika adalah bersifat abstrak, sifat ini menyebabkan siswa sulit memahami konsep yang mereka pelajari. 
Weldi Bahari : Pembelajaran Matematika di Sekolah Dasar ...

Menurut Suharta (2003: 6) berdasarkan laporan Third International Mathematics and Science Study (TIMSS), bahwa prestasi Matematika siswa baik secara nasional maupun internasional belum menggembirakan. Rendahnya prestasi Matematika siswa disebabkan oleh dua faktor utama yaitu siswa dan guru. Siswa tidak termotivasi dalam belajar Matematika, mereka mengalami masalah secara komprehensif atau parsial, sedangkan guru belum mampu secara optimal memberdayakan siswa dalam belajar.

Berkaitan dengan proses pembelajaran, Marpaung (2003: 2) menyatakan bahwa paradigma mengajar di Indonesia mempunyai ciri-ciri antara lain: (a) Guru aktif sedangkan siswa pasif, pembelajaran berpusat pada guru, (c) guru mentransfer pengetahuan kepikiran siswa, (d) pemahaman siswa cenderung bersifat instrumental, (e) pembelajaran bersifat mekanistik, (f) siswa diam (secara fisik) dan penuh konsentrasi (secara mental) memperhatikan apa yang diajarkan guru. Kondisi ini melahirkan anggapan bagi siswa bahwa belajar Matematika tidak lebih dan sekedar mengingat, kemudian melupakan fakta-fakta dan konsep tersebut.

Oleh karena itu diperlukan suatu pendekatan baru yang tepat dan efisien dalam pembelajaran Matematika di Sekolah Dasar, yaitu "Pembelajaran Matematika Berbasis Keterampilan Berpikir".

\section{METODE PENELITIAN}

Penelitian ini menggunakan model pembelajaran keterampilan berpikir dimulai dengan pembelajaran pemahaman konseptual pengerjaan Matematika (contoh: Konsep berhitung ; kurang, tambah, kali, membagi). Pemahaman merupakan perangkat baku program pendidikan yang merefikasikan kompetensi, sehingga dapat mengantarkan siswa untuk mcnjadi kompeten dalam berbagai bidang kehidupan (Yulailawaty, 2002). Sedangkan kompetensi seseorang yang telab menyelesaikan pendidikan menjadi titik tolak dan Kurikulum Berbasis Kompetensi (KBK). Oleh sebab itu, pembelajaran pemahaman konseptual berbasis keterampilan berpikir menjadi acuan sebagai alternatif implementasi KBK.

$$
\text { Model pembelajaran }
$$

konseptual interaktif (interactive conceptual interaction/ICI) yang terdiri dari beberapa komponen dan Slavine dan Scott (2002) sangat mendukung perkembangan keterampilan berpikir siswa dimulai dan tingkatan memahami konsep. Komponen ICI yang pertama, bertujuan untuk mengenibangkan ide-ide baru yang berfokus pada pemahaman konseptual dengan sedikit bahkan tanpa formulasi maternatik. Pembelajaran dimulai dengan demonstrasi fenornena yang bertindak sebagai fokus untuk pengamatan dan diskusi mengenai konsep-konsep yang dimediasi oleh guru. Komponen ICI yang kedua, melibatkan interaksi-interaksi kelas. 
Komponen mi didasari oleh premis bahwa pembuatan makna (meaning making) merupakan proses dialog antar komunitas kelas untuk mengembangkan gagasan melalui proses berpikir. Pembelajaran teman sebaya merupakan alternatif untuk melibatkan para siswa secara aktif dalam proses belajar. Komponen ICI yang ketiga, melibatkan penggunaan material berbasis penelitian. Pertanyaan dan jawaban dalam ulangan konseptual yang dirancang oleh guru digunakan pada tahapan awal dalam pembuatan makna. Umpan balik dari ulangan tersebut berfungsi untuk mengembangkan pemahaman siswa. Ulangan berbasis penelitian berfungsi sebagai alat diagnosa-sebagai assessment formatif yang lebih reliable dari pemahaman siswa. Ulangan berbasis penelitian dapat mengungkapkan kesulitan-kesulitan yang dialami siswa dan berfungsi sebagai acuan dalam pengajaran topik tersebut lebih.

\section{Contoh-contoh ulangan berbasis penelitian tentang pemahaman konsep berbasis pertanyaan :}

\section{Pengurangan}

Sebuah Buku Cerita mempunyai 53 halaman. Seorang Siswa telah telah membaca sebanyak 26 halaman. Berapa halaman lagi saya harus membaca buku itu supaya tamat?

Penyelesaian bisa dilakukan dengan cara "baris" dan "kolom"

A. Cara baris

Dengan bantuan garis bilangan kita bisa menerapkan konsep penjumlahan untuk menyelesaikan masalahmasalah pengurangan.

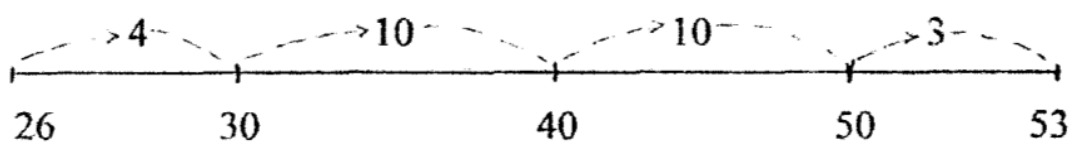

Langkah-langkah:

1) Garis bilangan dimulai dari bilangan 26 (sebagai titik awal) dan bilangan 53 sebagai titik akhir sesuai dengan permasalahan yang sedang dibicarakan.

2) Masukkan beberapa angka yang mudah dioperasikan siswa ke dalam interval bilangan, misalnya:
Bilangan 30 diperoleh dari $26+(4)$ Bilangan 40 diperoleh dari $30+(10)$ Bilangan 50 diperoleh dari $40+(10)$ Bilangan 53 diperoleh dari $50+(3)$

Sehingga solusi dari 53$26=4+10+10+3$ $=27$ 
B. Cara kolom

Langkah-langkah

1) Garis bilangan dimulai dari bilangan 26 (sebagai titik awal) dan bilangan 53 sebagai titik akhir.

2) Bilangan pada titik akhir dikurangi dengan angka yang mudah dioperasikan siswa sehingga melewati batas awal angka garis bilangan (26) dan membentuk iterval baru, misal :

$53-(30)=23$, dan $23+(3)=26$.

Sehingga solusi dari

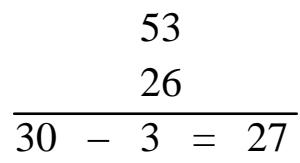

\section{Perkalian}

Cara mengajarkan perkalian yang sederhana lebih mudah dengan menggunakan konsep penjumlahan, misal :

7

$7+7$

$7+7+7$

$7+7+7+7$

$7+7+7+7+7$

$7+7+7+7+7+7$

$7+7+7+7+7+7+7$

$7+7+7+7+7+7+7+7$

$7+7+7+7+7+7+7+7+7$

$7+7+7+7+7+7+7+7+7+7$
$1 \times 7$

$2 \times 7$

$3 \times 7$

$4 \times 7$

$5 \times 7$

$6 \times 7$

$7 \times 7$

$8 \times 7$

$9 \times 7$

$10 \times 7$

Sehingga kita bisa mengajarkan bahwa :

$1 \times 7=7$

$2 \times 7=7+7$

$3 \times 7=(2 \times 7)+7$

$4 \times 7=(2 \times 7)+(2 \times 7)$

$5 \times 7=$ setengah dan $(10 \times 7)$ atau $(4 \times 7)+7$

$6 \times 7=(5 \times 7)+7$

dst

Komponen ICI keempat, melibatkan penggunaan refutational text untuk mengkonstruksi pemahaman secara mendalam. Peranan refutational text adalah untuk menggoyahkan pengetahuan awal siswa yang tidak ilmiah. Santyasa (2003) menggagas refutation text dengan sistematika: (1) sajian pertanyaan-pertanyaan

konseptual di awal teks, (2) sajian miskonsepsi yang 
berkaitan dengan pertanyaanpertanyaan di awal teks, (3) sangkalan terhadap pikiran yang miskonsepsi, (4) pembuktian sangkalan melalui sajian konsep dan prinsip diikuti dengan salah satu atau lebih dari proses demonstrasi, analogi, contohcontoh tandingan, dan konprontasi, (5) sajian contohcontoh berkaitan dengan dunia nyata, dan (6) sajian pertanyaanpertanyaan pemahaman, aplikasi, analisis, sintesis, dan evaluasi konsep di akhir teks. Belajar dengan refutational text dapat melibatkan siswa menggunakan metakognisi, keterampilan berpikir kritis dan kreatif, prosesproses berpikir, keterampilan berpikir inti, dan menghubungkan pengetahuan isi dengan berpikir untuk memahami fenomena dunia nyata.

Belajar merupakan proses pengkonstruksian pemahaman terhadap dunia tempat kita tinggal. Siswa mengkonstruksi pengetahuan dalam pikiran mereka sendiri (Brooks, 1993); Slavin, 1994 ; Mayer, 1999). Konstruksi pengetahuan Matematika mengandung makna bahwa pengetahuan tidak diterima secara pasif, tetapi secara aktif oleh siswa. Bangunan pemahaman siswa terhadap konsep-konsep Matematika yang baru diperoleh melalui refleksi terhadap lingkungan fisik dan aktifitas mental siswa. Belajar

Matematika direfleksikan dalam suatu proses sosial yang memberikan kesempatan bagi siswa untuk bekerjasama melalui dialog dan diskusi dengan teman dan gurunya (Reys, et al. 1998).

\section{HASIL PENELITIAN DAN PEMBAHASAN}

Steffe dan D’Ambrosio
(1995) menyarankan bahwa
rancangan pembelajaran Matematika
memperhatikan pengetahuan awal Matematika dan mengaktifkan pengetahuan awal dalam situasi belajar yang dapat memunculkan konflik kognitif dan mendorong siswa untuk menjalankan proses inkuilibrasi. Pembelajaran Matematika berbasis keterampilan berpikir dilakukan dengan prosedur sebagai berikut:

Tahap pertama ada perencanaan yaitu identifikasi tujuan menyesuaikan kurikulum dengan kemampuan kognitif siswa. Pemahaman dapat meningkat apabila tujuan pembelajaran disesuaikan dengan kemampuan kognitif siswa, kondisi sosial dan emosional siswa (Brooks, 1993). Pengetahuan awal siswa tentang strategi pemecahan masalah Matematika dan penguasaan konsep-konsep Matematika dibutuhkan sebagai referensi bagi guru dalam mengidentifikasi tujuan pembelajaran (Resnick dan Ford, 1981 ; Hembree dan Marsh, 1994).

Perencanaan dilanjutkan
dengan mendesain masalah
Matematika yang memiliki tipe ill-
defined. Masalah yang berstruktur


Weldi Bahari : Pembelajaran Matematika di Sekolah Dasar ...

ill-defined diangkat dari konteks kehidupan sehari-hari yang mendeskripsikan sesuatu situasi. Skenario permasalahan diungkapkan secara singkat dengan kalimat yang pendek, memberikan sedikit fakta tentang lingkungan sekitar konteks permasalahan. Skenario permasalahan diawali dengan suatu sudut pandang sebagai asumsi bagi siswa. Skenario secara gamblang menuntut suatu penyelidikan (Fogarty, 1997).

Proses pembelajaran dengan pendekatan keterampilan berpikir dijalankan dengan langkah-langkah kegiatan belajar sebagai berikut : (1) Menemukan masalah (Klurik dan Rudnick, 1995); (2) Mendifinisikan masalah; (3) Mengumpulkan faktafakta; (4) Menyusun dengan sementara; (5) Menyelidiki; (6) Menyempurnakan masalah yang telah didefinisikan;

Menyimpulkan alternatif-alternatif pemecahan masalah secara kolaboratif; (8) Menguji solusi pemecahan (Fogarty, 1997).

Degeng (1998) menyatakan bahwa evaluasi dalam pandangan konstruktivistik memiliki makna : (1) menekankan pada penyusunan makna secara aktif yang melibatkan panduan keterampilan dengan menggunakan masalah dan konteks nyata, (2) menggali munculnya cara berpikir divergen, pemecahan ganda, bukan satu jawaban benar, (3) evaluasi merupakan bagian yang utuh dari belajar. Bertolak dari pendapat ini, penilaian proses dan hasil belajar Matematika menghendaki penilaian yang menyatu dalam proses pembelajaran.

Suatu teknik penilaian yang menyatu dalam proses pembelajaran adalah penilaian dengan menggunakan autentik assessmen. Menurut O’Malley dan Pierce (1996) penilaian autentik secara langsung mengukur performance nyata siswa. Boud dan Felleti (1997) menyatakan bahwa penilaian dengan orientasi pada proses bertujuan untuk menilai keterampilan berkomunikasi, bekerjasama, penerimaan siswa terhadap tanggung jawab belajar, mempelajari belajar (learning to learn), penyelesaian dan penggunaan sumber-sumber dan pengembangan keterampilan memecahkan masalah. Penilaian hasil atau produk yang menyatu dengan proses belajar dapat menggunakan assessment portopolio yang mengacu kepada penilaian yang dibuat bersama oleh guru dan siswa (Winters H. Aschbacher, 1992).

Kriteria pemberian skor kemampuan pemecahan masalah Matematika untuk siswa sekolah dasar diadaptasi dari analytic scoring scale yang disusun oleh Charles, Lester dan O'Daffer dalam Reys, et al (1995).

Skenario pembelajaran diawali dengan perencanaan yang mencakup kegiatan-kegiatan : (1) identifikasi tujuan pembelajaran (objectives), (2) identifikasi standar assessment, (3) perancangan pesan. Proses pembelajaran dilakukan dengan pendekatan problem-based learning (PBL) sesuai dengan tahapan yang dikemukakan oleh 
Fogarty (1997). Evaluasi proses dan hasil dilakukan dengan evaluasi formatif dan sumatif dalam siklus belajar yang sesuai dengan proses belajar.

\section{Pembahasan}

Tujuan

pendidikan

Matematika pada level pendidikan dasar di Indonesia adalah untuk mencapai 2 sasaran. Pertama. Mempersiapkan siswa agar sanggup menghadapi perubahan keadaan di dalam kehidupan dan dunia yang selalu berubah,rnelalui latihan bertindak atas dasar pemikiran secara logis, rasional, kreatif, cermat, jujur, efektif dan efisien. Kedua, mempersiapkan agar siswa dapat menggunakan Matematika dan pola pikir Matematika dalam kehidupan sehari-hari dan bermanfaat dalam mempelajari berbagai ilmu pengetahuan (Depdikbud, 1994). Tujuan tersebut menjadi sarana untuk mengembangkan kemampuan pemecahan masalah, menggali, menciptakan dan mengakomodir perubahan kondisi (Susana, 1994; Longworth, 1999).

Demitra

menyatakan hahwa kemampuan pemecahan masalah Matematika di jenjang pendidikan dasar dimaksudkan untuk melatih, dan merupakan wahana bagi siswa untuk mengembangkan kemampuan berpikir tingkat tinggi. Pengembangan kemampuan berpikir tingkat tinggi itu sendiri sangat potensial mengembangkan kompetensi siswa.
Dan uraian di atas, dapatlah dipahami bahwa hakikat belajar atematika ialah untuk mempersiapkan siswa agar dapat berpikir rasional, mampu mengambil sikap atas persoalan hidup yang dihadapi, dan konsep ini perlu dilatihkan sejak usia dini yaitu usia sekolah dasar, sehingga dengan pola berpikir matematis itu hidupnya akan lebih tertolong dan tidak mudah putus asa, kelak dalam hidupnya saat dewasa.

\section{SIMPULAN}

Dari uraian terdahulu, dapatlah dibuat beberapa kesimpulan, yaitu:

a. Kurikulum berbasis kompetensi mensyaratkan agar pembelajaran Matematika dapat memberikan hasil belajar berupa kompetensikompetensi yang harus dikuasai oleh siswa. Kompetensikompetensi tersebut meliputi aspek-aspek kognitif, afektif dan psikomotor.

b. Fenomena Matematika yang bersifat kompleks juga menghendaki pembelajaran bersifat holistik berbasis keterampilan berpikir yang berorientasi pada dimensi belajar dan dimensi berpikir siswa. Pembelajaran dengan model interactive conceptual interaction merupakan alternatif pembelajaran berbasis keterampilan berfikir. Pembelajaran semacam itu memberi peluang kepada siswa untuk mencapai pemahaman secara mendalam, menerapkan 
pemahamannya di dunia nyata, mengembangkan metakognisi, berpikir kritis dan kreatif, melakukan proses-proses berpikir secara efektif, menggunakan keterampilan berpikir inti, dan dapat menghubungkan pengetahuan isi dengan berpikir untuk memahami fenomena fisis di dunia nyata.

c. Pembelajaran Matematika berbasis keterampilan berpikir dapat mengarahkan para siswa menjadi manusia jujur, terbuka, kritis, komit dengan kemurnian dan ketepatan, sanggup memecahkan masalah, mudah dalam mengambil keputusan, dan selalu berpikir tingkat tinggi. Kemampuan-kemampuan tersebut merupakan kompetensikompetensi yang vital untuk menatap kehidupan di dunia nyata yang serba tak menentu dan tak jelas.

\section{DAFTAR RUJUKAN}

Boud, D. Dan Felleti, G.I. 1997. The challenge of problem based learning. London: Kagan Page.

Brooks, J. G dan Brooks, M.G. 1993. In search of understanding: the case for constructivist classrooms. Alexandria, Virginia: Association for Supervision and Curriculum Development.

Conny, Semiawan. 1993. Pendekatan Pembelajaran Acuan Konseptual Pengelolaan KBM di Sekolah. Jakarta:
Ditjen Dikti, Konsorsium Ilmu Pendidikan.

Degeng, I. N.S. 1998. Mencari Paradigma Baru Pemecahan Masalah Belajar dari Keteraturan Menuju Kesemrawutan. Malang: IKIP (Pidato Pengukuhan Guru Besar).

Depdikbud 1994. Kurikulum Pendidikan Sekolah Dasar: GBPP Bidang Studi Matematika. Jakarta: Depdikbud.

Forgaty, R. 1997. Problem-Based Learning and other curriculum models for the multiple intelligences classroom. Arlington Heights-Illinois: Sky Light.

Hembre, R dan Marsh, H. 1994. Problem solving in early childhood: Building foundations. Ed.Jensen R.J, Research ideas for the classroom early childhood mathematies. New York: Macmillan Publishing Company.

Lewis, A \& Smith, D. 1993. Defining higher order thinking. Dalam Donmoyer, R \& Merryfield, M. M (eds): Theory into practice: Teaching for higher order thinking. 32 (3) pp. 131-137.

Marzano, R.J. 1993. How classroom teachers approach the teaching of thinking. Dalam Donmoyer \& Merryfield, MM (Eds) : Theory into practice : Teaching 
for higher order thinking. 32

(3) pp. 148-153.

O'malley, J.M. dan Pierce, L.V. 1996. Authentic assessment for English language learners : practical approaches for teachers. Ontario: Addison Weshley Publishing Company. Resnick, L.B dan Ford, W.W. 1981. The psychology of mathematics for instruction. Hillsdale, N.J: Lawrence Erlbaum Associates: Publishers.

Santyasa, I.W. 2003. Miskonsepsi dan Model Pembelajaran Perubahan Konseptual. Makalah Seminar Nasional TP, Jakarta: HI 18 Juli 2003.

Slavin. R. E. 1994. Educational psychology: Theory and practice. Boston: Allyn and Bacon.

Suharta, I. Gusti, Putu. 2003. Matematika Realistik: Apa dan Bagaimana. Denpasar: IKIP Negeri Singaraja.

Suherman, Erman. 2001. Pengajaran

Matematika dengan

Pendekatan Realistik,
Pembelajaran di SD dan Menengah. Padang: Jurnal Guru (1) Desember 2004.

Sukmadinata, Nana, S. 2005. Pengembangan Kurikulum : Teori dan Praktek (Cet.7). Bandung: Remaja Rosdakarya.

Steffe, L. P. dan D'Ambrossio, B. S. 1995. Toward a working model of constructivist teaching: a reaction to simon. Journal for research in mathematies education. Pp. 146-159.

Undang-Undang. 2003. Tentang Sistem Pendidikan Nasional RI Nomor 20 tahun 2003. Jakarta: Rineka Cipta.

Yulailawaty, E. 2002. Karakteristik Pembelajaran MIPA Berdasarkan Kurikulum Berbasis Kompetensi. Singaraja: FPMIPA IKIP (Makalah).

Zhou, Nanzhao. 2000. A ffection on "learning to learn" the four pillars of learning and their implications for curriculum reforms. Bangkok: IBE. 